\section{A highly porous metal-organic framework, constructed from a cuboctahedral super-molecular building block, with exceptionally high methane uptake $\dagger$}

\author{
Ulrich Stoeck, Simon Krause, Volodymyr Bon, Irena Senkovska and Stefan Kaskel*
}

Received 6th July 2012, Accepted 19th September 2012

DOI: $10.1039 / \mathrm{c} 2 \mathrm{cc} 34840 \mathrm{c}$

A highly porous metal-organic framework $\mathrm{Cu}_{2}$ (BBCDC) (BBCDC $=9,9^{\prime}$-([1, $1^{\prime}$-biphenyl $]-4,4^{\prime}$-diyl) bis(9H-carbazole3,6-dicarboxylate) (DUT-49) with a specific surface area of $5476 \mathrm{~m}^{2} \mathrm{~g}^{-1}$, a pore volume of $2.91 \mathrm{~cm}^{3} \mathrm{~g}^{-1}, \mathrm{a} \mathrm{H}_{2}$ excess uptake of $80 \mathrm{mg} \mathrm{g}^{-1}$ (77 K, $50 \mathrm{bar}$ ), a $\mathrm{CO}_{2}$ excess uptake of $2.01 \mathrm{~g} \mathrm{~g}^{-1}$ $(298 \mathrm{~K}, 50 \mathrm{bar})$ and an exceptionally high excess methane storage capacity of $308 \mathrm{mg} \mathrm{g}^{-1}(298 \mathrm{~K}, 110 \mathrm{bar})$ was obtained using an extended tetratopic linker.

Porous metal-organic frameworks (MOFs) constitute a class of important crystalline materials with an intriguing diversity concerning structure and function. Due to their facile synthesis and their - to some extent - tunable properties (e.g. pore size and functionality) MOFs qualified themselves for a number of different fields of applications ranging from energy/gas storage ${ }^{1}$ and capture of greenhouse or other harmful gases ${ }^{2}$ over catalysis ${ }^{3}$ and sensing ${ }^{4}$ to drug delivery. ${ }^{5}$

Designing metal-organic frameworks for gas storage has to deal with several different requirements and specifications. Depending on the application, the desired gas species as well as the targeted pressure range have to be considered. It is widely accepted that high internal surface areas and large pore volumes are highly beneficial for enhancing storage capacities, especially in the moderate to high pressure regime. In addition the accessibility and the density of (open) metal sites in the material have been shown to increase the affinity of the MOF to some gases (e.g. $\left.\mathrm{H}_{2}, \mathrm{CO}_{2}, \mathrm{CH}_{4}\right){ }^{6}$ Theoretical studies uncovered that for the storage of certain gases the pore diameter has an optimum size. ${ }^{7}$

The strategy of utilizing metal-organic polyhedra (MOPs) as building blocks to design porous materials is an attractive way because it provides a high degree of control over the resulting porous structure and topology. Selection of the starting metalorganic polyhedron ensures the size and geometry of the smallest pore as well as the connectivity of the employed super-molecular

Dresden University of Technology, Department of Inorganic

Chemistry, Bergstrasse 66, 01069 Dresden, Germany.

E-mail: stefan.kaskel@chemie.tu-dresden.de;

Fax: + 49351463 37287; Tel: + 4935146334885

$\dagger$ Electronic supplementary information (ESI) available: Synthetic procedures for $\mathrm{H}_{4} \mathrm{BBCDC}$ and DUT-49, further structural figures, TGA curves, elemental analysis, PXRD patterns, additional sorption isotherms. CCDC 889572, 890363 and 890364. For ESI and crystallographic data in CIF or other electronic format see DOI: $10.1039 / \mathrm{c} 2 \mathrm{cc} 34840 \mathrm{c}$ building block (SBB). Furthermore the choice of shape, size and symmetry of the molecular entity connecting the SBBs can control the number of pores as well as their shape and size. The utility of this SBB approach for constructing porous metal-organic frameworks was earlier shown by Zaworotko and co-workers. ${ }^{8}$ In recent years it was successfully applied to the synthesis of several MOFs based on the copper isophtalate MOP- $1^{9}$ as an SBB and a $\mathrm{C}_{3}$-symmetric linking moiety. Some of them (e.g. NOTT-112 and $-119,{ }^{10 a, b} \mathrm{PCN}-68^{10 c}$ and NU-100 ${ }^{10 d}$ ) displayed remarkable gas storage capacities. Herein we report the design and synthesis of a new highly porous metal-organic framework synthesized using the SBB approach with a pore system optimized for efficient methane adsorption. We employed a cuboctahedral metal-organic polyhedron based on copper paddle-wheels and carbazole-3,6-dicarboxylate (Fig. 1a). ${ }^{11}$ The carbazole based MOP has an inner diameter of $12 \AA$, which is close to the optimal size ( $11 \AA$ ) for methane storage calculated for activated carbons. ${ }^{7}$ The cuboctahedral MOP can be regarded as a 12 connecting SBB considering the carbazole nitrogen as the connecting point (Fig. 1b). Connecting these carbazole moieties in a linear fashion should result in a framework with fcu topology. In order to assemble such a polyhedron based metal-organic framework we designed and developed a synthetic procedure for the new tetratopic ligand $\mathrm{H}_{4} \mathrm{BBCDC}$ (3) $\left(9,9^{\prime}\right.$-([1, $1^{\prime}$-biphenyl]4,4'-diyl) $\underline{b}$ is $(9 H$-carbazole-3,6-dicarboxylic acid)) starting from

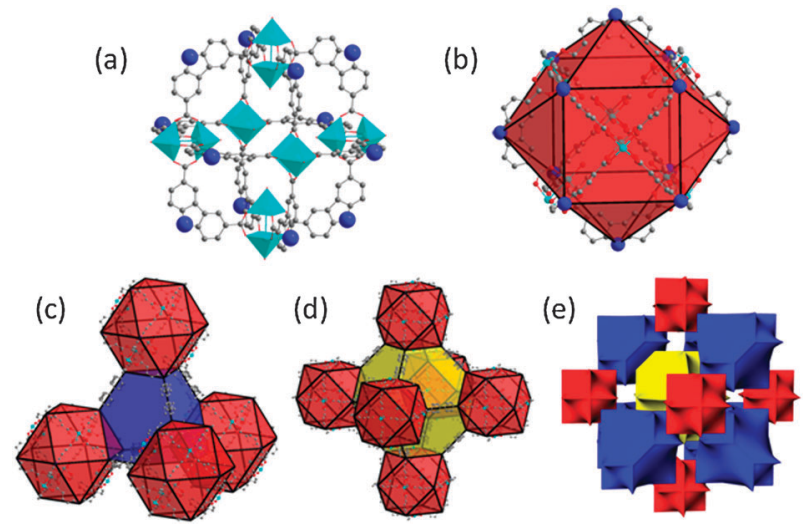

Fig. 1 (a) Carbazole based metal-organic polyhedron. ${ }^{11}$ Structure of DUT-49: (b) cuboctahedral SBB; (c) tetrahedral cage (blue); (d) octahedral cage (yellow); (e) tiling of DUT-49 - cuboctahedral pore (red), octahedral pore (yellow), tetrahedral pore (blue). 


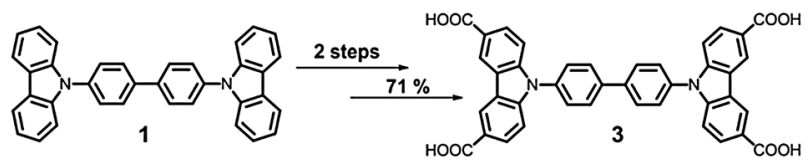

Scheme 1 View of the $\mathrm{H}_{4} \mathrm{BBCDC}$ (3) linker molecule and the corresponding starting material $\mathbf{1}$.

the readily available 4,4-bis( $N$-carbazoyl)-1,1-biphenyl (1) (Scheme 1). Fourfold bromination of $\mathbf{1}$ is followed by lithiation. Quenching the organolithium species with $\mathrm{CO}_{2}$ generates $\mathrm{H}_{4} \mathrm{BBCDC}(4)$ in a good overall yield of $71 \%$ over two steps (see ESI $\dagger$ ). Solvothermal reaction of $\mathrm{H}_{4} \mathrm{BBCDC}$ with $\mathrm{Cu}\left(\mathrm{NO}_{3}\right)_{2} \cdot 3 \mathrm{H}_{2} \mathrm{O}$ in $N$-methyl-2-pyrrolidone (NMP) afforded DUT-49 (Dresden University of Technology No. 49) as blue cube shaped crystals of composition $\left[\mathrm{Cu}_{2}(\mathrm{BBCDC})\right]\left(\mathrm{H}_{2} \mathrm{O}\right)_{x}(\mathrm{NMP})_{y} \cdot \ddagger$ Isomorphous compounds were obtained using zinc or cobalt nitrate as a metal source (see ESI $\dagger$ ). Further characterization and adsorption studies were carried out only on DUT-49(Cu). Topological analysis of the crystal structure confirms the formation of a $(4,4)$-connected nbo net in case the paddle-wheels of the SBB are considered as nodes. Considering the cuboctahedral SBBs as nodes results in a 12-connected augmented fcu net, as expected. Therefore the structure of DUT-49 can be understood as an extended cubic closed packing of cuboctahedral super-molecular building blocks (Fig. 1e and Fig. S1, ESI $\dagger$ ). The framework contains tetrahedral cavities (Fig. 1c) and octahedral cavities (Fig. 1d) in addition to the MOP voids. Thus DUT-49 has a trimodal pore structure with sizes ranging from $12 \AA$ (MOP cuboctahedron) over $18 \AA$ (tetrahedron) to $26 \AA$ (octahedron). Pore sizes were determined as diameters of the largest sphere which could be inscribed in the void taking into account van der Waals radii of the atoms (Fig. S2, ESI $\dagger$ ). The MOP provides 12 accessible metal sites after removal of coordinated solvent molecules. The total solvent accessible volume of the desolvated framework (after removal of all guests and coordinated solvent molecules) was determined to be $84.7 \%$ (using PLATON) rendering the material one of the most porous MOF materials synthesized to date. To evaluate the gas accessible porosity of DUT-49 gas physisorption experiments were performed. First, the solvent of the as made solid was exchanged with ethanol. The ethanol exchanged DUT-49 sample was subjected to a supercritical drying process employing liquid carbon dioxide. The crystallinity of the framework is retained after drying, as confirmed by X-ray powder diffraction analysis (Fig. S3, ESI $\dagger$ ). Thermogravimetric analysis shows that DUT-49 is thermally stable up to $300{ }^{\circ} \mathrm{C}$ (Fig. S7, $\mathrm{ESI} \dagger)$. Subsequent nitrogen physisorption experiments display an isotherm with a small hysteresis loop between 0.15 and 0.2 relative pressures (Fig. 2). The isotherm reaches saturation at an uptake of $1880 \mathrm{~cm}^{3}$ nitrogen per gram of MOF. This corresponds to a total pore volume of $2.91 \mathrm{~cm}^{3} \mathrm{~g}^{-1}$ (at $p / p_{0}=0.99$ ). These values substantially exceed the pore volume of most large pore MOFs, such as MOF-177 (1.89 $\left.\mathrm{cm}^{3} \mathrm{~g}^{-1}\right),{ }^{12 a}$ DUT-9 $\left(2.18 \mathrm{~cm}^{3} \mathrm{~g}^{-1}\right),{ }^{12 b}$ UMCM-2 $\left(2.31 \mathrm{~cm}^{3} \mathrm{~g}^{-1}\right),{ }^{12 c}$ NOTT-119 $\left(2.35 \mathrm{~cm}^{3} \mathrm{~g}^{-1}\right)$, NU$100\left(2.82 \mathrm{~cm}^{3} \mathrm{~g}^{-1}\right),{ }^{10 d}$ and are only surpassed by MOF-200 and $-210\left(3.59 \mathrm{~cm}^{3} \mathrm{~g}^{-1} \text { and } 3.6 \mathrm{~cm}^{3} \mathrm{~g}^{-1}\right)^{10 e}$ and bioMOF-100 $\left(4.3 \mathrm{~cm}^{3} \mathrm{~g}^{-1}\right){ }^{12 d}$ Analysis of the nitrogen physisorption isotherm (at $77 \mathrm{~K}$ ) using the BET theory results in a very high specific surface area of $5476 \mathrm{~m}^{2} \mathrm{~g}^{-1}$ (Fig. S9, ESI $\dagger$ ). This specific surface area is one of highest reported to date for any

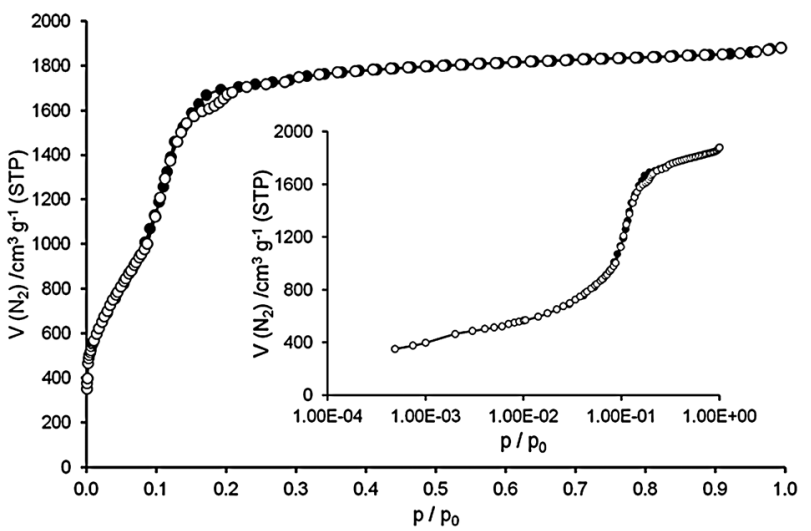

Fig. 2 Nitrogen physisorption isotherm of DUT-49 at $77 \mathrm{~K}$ (inset: isotherm on a semi logarithmic scale); adsorption: open symbols, desorption: closed symbols.

porous material. Thus DUT-49 ranks among the few MOFs with a specific surface area over $5000 \mathrm{~m}^{2} \mathrm{~g}^{-1}$. It is only exceeded by MOF-210 $\left(6240 \mathrm{~m}^{2} \mathrm{~g}^{-1}\right)$ and NU-100 $\left(6143 \mathrm{~m}^{2} \mathrm{~g}^{-1}\right)$. Since the storage capacities of porous materials depend on the surface area of the adsorbent at moderate pressures and on pore volume at higher pressures, ${ }^{1,10 a, 13}$ the large pore volume and specific surface area of DUT-49 prompted us to investigate its high-pressure storage capacities for hydrogen, methane, and carbon dioxide. Sorption data were collected up to 80 bar at $77 \mathrm{~K}$ for hydrogen, using a volumetric method, and up to $55 \mathrm{bar}$ at $298 \mathrm{~K}$ for carbon dioxide using a gravimetric method. The hydrogen adsorption isotherm revealed an maximum excess hydrogen storage capacity of $80 \mathrm{mg} \mathrm{g}^{-1}$ (total: $165 \mathrm{mg} \mathrm{g}^{-1}$ ) at 50 bar (Fig. 3 and Fig. S10, ESI $\dagger$ ), which exceeds nearly all known MOFs including MOF-177 (excess: $73 \mathrm{mg} \mathrm{g}^{-1}$; total: $115 \mathrm{mg} \mathrm{g}^{-1}$ ), NOTT-112 (excess: $76 \mathrm{mg} \mathrm{g}^{-1}$; total: $105 \mathrm{mg} \mathrm{g}^{-1}$ ), and is in the same range as MOF-210 (excess: $86 \mathrm{mg} \mathrm{g}^{-1}$; total: $167 \mathrm{mg} \mathrm{g}^{-1}$ ). Only NU-100 shows substantially higher maximum excess hydrogen uptake $\left(99 \mathrm{mg} \mathrm{g}^{-1}\right)$, but in terms of total uptake (164 $\mathrm{mg} \mathrm{g}^{-1}$ ) matched DUT-49.

Because of its well known property as a greenhouse gas, the removal of $\mathrm{CO}_{2}$ from exhaust gas and its subsequent storage receives increasing attention. Therefore we measured the high pressure $\mathrm{CO}_{2}$ adsorption isotherm on DUT-49 with a magnetic

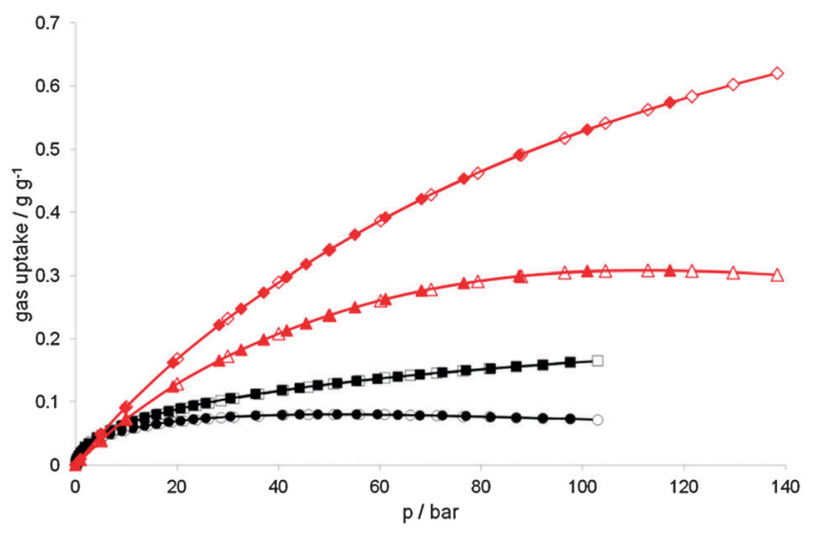

Fig. 3 Methane at $298 \mathrm{~K}$ (red) and hydrogen at $77 \mathrm{~K}$ (black) physisorption isotherms on DUT-49. Circles and triangels - excess, squares and diamonds - total. Adsorption: closed symbols, desorption: open symbols. 
suspension balance. Under conditions that are potentially relevant for intermediate term storage applications (50 bar and 298 K) DUT-49 shows one of the highest excess uptake values reported for MOF materials up to now. With the $2.01 \mathrm{~g} \mathrm{~g}^{-1}$ excess amount adsorbed at 50 bar (total: $2.45 \mathrm{~g} \mathrm{~g}^{-1}$ ) (Fig. S8, ESI $\dagger$ ) DUT-49 exceeds nearly all known MOFs and ranks among NU-100 (excess $2.04 \mathrm{~g} \mathrm{~g}^{-1}$; total: $2.32 \mathrm{mg} \mathrm{g}^{-1}$ ) and MOF-210 (excess: $2.40 \mathrm{~g} \mathrm{~g}^{-1}$; total: $2.87 \mathrm{mg} \mathrm{g}^{-1}$ ).

Methane is the main component of natural gas, which is an important candidate for clean transportation fuels, because combustion of methane produces the smallest amount of carbon dioxide per unit of heat among fossil fuels. Thus efficient storage and transportation of methane can become a key issue for the development of more environmentally friendly transportation systems and in the medium-term can reduce the strong dependency of transport and individual mobility on crude oil. These considerations encouraged us to evaluate the properties of DUT-49 as a methane storage material. At 80 bar and 298 K DUT-49 shows a gravimetric excess uptake of $291 \mathrm{mg} \mathrm{g}^{-1}$ (Fig. 3 and Fig. S11, ESI $†$ ) exceeding clearly the current record holding compounds DUT-23 (Co) $\left(266 \mathrm{mg} \mathrm{g}^{-1}\right.$ excess) $)^{1 d}$ and MOF-210 (264 $\mathrm{mg} \mathrm{g}^{-1}$ excess). At a pressure of 110 bar DUT-49 reaches a maximum of excess storage capacity of $308 \mathrm{mg} \mathrm{g}^{-1}$ corresponding to a total uptake of $540 \mathrm{mg} \mathrm{g}^{-1}$ (236 $\mathrm{cm}^{3} \mathrm{~cm}^{-3}$ taking crystallographic density into account). To the best of our knowledge, this exceeds by far any methane storage capacity for any porous materials reported yet.

In summary we have reported the new carbazole based tetratopic ligand 9,9'-([1,1'-biphenyl]-4,4'-diyl)bis( $9 H$-carbazole-3,6-dicarboxylic acid) $\left(\mathrm{H}_{4} \mathrm{BBCDC}\right)(3)$ which has enabled the synthesis of a new highly porous MOF. DUT-49 shows high thermal stability up to $300{ }^{\circ} \mathrm{C}$. It has an extremely high specific surface area and a very large pore volume resulting in excellent gas storage capacities for $\mathrm{H}_{2}$ and $\mathrm{CO}_{2}$. Moreover, DUT-49 shows exceptionally high methane adsorption exceeding all known porous materials, making it a benchmark material for methane adsorption studies.

This work was financially supported by the German Research Foundation (SPP 1362). The authors are grateful to Dr U. Mueller for support during the measurements and the Helmholtz Centre Berlin for financing the travel costs to BESSY II.

\section{Notes and references}

$\ddagger$ Crystal data for DUT-49(Cu) after SQUEEZE (synchrotron radiation, $\lambda=0.88561 \AA$ ): DUT-49(Cu), $\mathrm{C}_{66} \mathrm{H}_{66.8} \mathrm{Cu}_{2} \mathrm{~N}_{7.2} \mathrm{O}_{15.2}, M_{\mathrm{r}}=1331.15$, cubic $F m \overline{3} m, a=46.588(5) \AA, V=101117(19) \AA^{3}, Z=24, D_{\mathrm{c}}=0.525 \mathrm{~g} \mathrm{~cm}^{-3}$, 5122 independent reflections observed, $R_{1}=0.063(I>2 \sigma(I)), \mathrm{w} R_{2}=$ 0.1857 (all data), and GOF $=0.861 ;$ CCDC 889572, 890363 and 890364 for DUT-49(Cu), DUT-49(Zn) and DUT-49(Co), respectively.

1 (a) L. J. Murray, M. Dincă and J. R. Long, Chem. Soc. Rev., 2009, 38, 1294-1314; (b) S. Shimomura, S. Bureekaew and S. Kitagawa, Molecular Networks, Structure and Bonding, Springer-Verlag, Berlin Heidelberg, 2009, vol. 132, pp. 51-86; (c) X. Lin, I. Telepeni, A. J. Blake, A. Dailly, C. M. Brown, J. M. Simmons, M. Zoppi, G. S. Walker, K. M. Thomas, T. J. Mays, P. Hubberstey, N. R. Champness and M. Schröder, J. Am. Chem. Soc., 2009, 131, 2159-2171; (d) N. Klein,
I. Senkovska, I. A. Baburin, R. Grünker, U. Stoeck, M. Schlichtenmayer, B. Streppel, U. Müller, S. Leoni, M. Hirscher and S. Kaskel, Chem.-Eur. J., 2011, 17, 13007-13016. 2 (a) I. Senkovska, E. Barea, J. A. R. Navarro and S. Kaskel, Microporous Mesoporous Mater., 2012, 156, 115-120; (b) C. Montoro, F. Linares, E. Q. Procopio, I. Senkovska, S. Kaskel, S. Galli, N. Masciocchi, E. Barea and J. A. R. Navarro, J. Am. Chem. Soc., 2011, 133, 11888-11891; (c) K. Sumida, D. L. Rogow, J. A. Mason, T. M. McDonald, E. D. Bloch, Z. R. Herm, T.-H. Bae and J. R. Long, Chem. Rev., 2012, 112, 724-781.

3 (a) L. Ma, C. Abney and W. Lin, Chem. Soc. Rev., 2009, 38, 1248-1256; (b) L. Ma, J. M. Falkowski, C. Abney and W. Lin, Nat. Chem., 2010, 2, 838-846; (c) F. Vermoortele, R. Ameloot, L. Alaerts, R. Matthessen, B. Carlier, E. V. Ramos Fernandez, J. Gascon, F. Kapteijn and D. E. De Vos, J. Mater. Chem., 2012, 22, 10313-10321; (d) K. Gedrich, M. Heitbaum, A. Notzon, I. Senkovska, R. Fröhlich, J. Getzschmann, U. Müller, F. Glorius and S. Kaskel, Chem.-Eur. J., 2011, 17, 2099-2106.

4 (a) M. Allendorf, A. Bétard and R. Fischer, in Metal-Organic Frameworks, ed. D. Farrusseng, Wiley-VCH, Weinheim, Germany, 2011, pp. 309-335; (b) L. E. Kreno, K. Leong, O. K. Farha, M. Allendorf, R. P. Van Duyne and J. T. Hupp, Chem. Rev., 2012, 112, 1105-1125.

5 (a) P. Horcajada, R. Gref, T. Baati, P. K. Allan, G. Maurin, P. Couvreur, G. Férey, R. E. Morris and C. Serre, Chem. Rev., 2012, 112, 1232-1268; (b) P. Horcajada, T. Chalati, C. Serre, B. Gillet, C. Sebrie, T. Baati, J. F. Eubank, D. Heurtaux, P. Clayette, C. Kreuz, J.-S. Chang, Y.-K. Hwang, V. Marsaud, P.-N. Bories, L. Cynober, S. Gil, G. Férey, P. Couvreur and R. Gref, Nat. Mater., 2010, 9, 172-178.

6 (a) J. Getzschmann, I. Senkovska, D. Wallacher, M. Tovar, D. Fairen-Jimenez, T. Düren, J. M. van Baten, R. Krishna and S. Kaskel, Microporous Mesoporous Mater., 2010, 130, 50-58; (b) P. D. C. Dietzel, R. E. Johnsen, H. Fjellvåg, S. Bordiga, E. Groppo, S. Chavan and R. Blom, Chem. Commun., 2008, 5125-5127; (c) M. Dincă and J. R. Long, Angew. Chem., Int. Ed., 2008, 47, 6766-6779.

7 (a) S. K. Bhatia and A. L. Myers, Langmuir, 2006, 22, 1688-1700; (b) V. C. Menon and S. Komarneni, J. Porous Mater., 1998, 5, 43-58.

8 (a) A. J. Cairns, J. A. Perman, L. Wojtas, V. C. Kravtsov, M. H. Alkordi, M. Eddaoudi and M. J. Zaworotko, J. Am. Chem. Soc., 2008, 130, 1560-1561; (b) J. J. Perry IV, J. A. Perman and M. J. Zaworotko, Chem. Soc. Rev., 2009, 38, 1400-1417.

9 M. Eddaoudi, J. Kim, J. B. Wachter, H. K. Chae, M. O'Keeffe and O. M. Yaghi, J. Am. Chem. Soc., 2001, 123, 4368-4369.

10 (a) Y. Yan, X. Lin, S. Yang, A. J. Blake, A. Dailly, N. R. Champness, P. Hubbersteya and M. Schröder, Chem. Commun., 2009, 1025-1027; (b) Y. Yan, S. Yang, A. J. Blake, W. Lewis, E. Poirier, S. A. Barnett, N. R. Champnessa and M. Schröder, Chem. Commun., 2011, 47, 9995-9997; (c) D. Yuan, D. Zhao, D. Sun and H.-C. Zhou, Angew. Chem., Int. Ed., 2010, 49, 5357-5361; (d) O. K. Farha, A. Ö. Yazaydın, I. Eryazici, C. D. Malliakas, B. G. Hauser, M. G. Kanatzidis, S. T. Nguyen, R. Q. Snurr and J. T. Hupp, Nat. Chem., 2010, 2 , 944-948; (e) H. Furukawa, N. Ko, Y. B. Go, N. Aratani, S. B. Choi, E. Choi, A. O. Yazaydin, R. Q. Snurr, M. O'Keeffe, J. Kim and O. M. Yaghi, Science, 2010, 329, 424-428.

11 J.-R. Li, D. J. Timmons and H.-C. Zhou, J. Am. Chem. Soc., 2009, 131, 6368-6369.

12 (a) H. K. Chael, D. Y. Siberio-Pérez, J. Kim, Y. Go, M. Eddaoudi, A. J. Matzger, M. O'Keeffe and O. M. Yaghi, Nature, 2004, 427, 523-527; (b) K. Gedrich, I. Senkovska, N. Klein, U. Stoeck, A. Henschel, M. R. Lohe, I. A. Baburin, U. Müller and S. Kaskel, Angew. Chem., Int. Ed., 2010, 49, 8489-8492; (c) K. Koh, A. G. Wong Foy and A. J. Matzger, J. Am. Chem. Soc., 2009, 131, 4184-4185; (d) J. An, O. K. Farha, J. T. Hupp, E. Pohl, J. I. Yeh and N. L. Rosi, Nat. Commun., 2012, 3, 1-6.

13 Y. Yan, I. Telepeni, S. Yang, X. Lin, W. Kockelmann, A. Dailly, A. J. Blake, W. Lewis, G. S. Walker, D. R. Allan, S. A. Barnett, N. R. Champness and M. Schröder, J. Am. Chem. Soc., 2010, 132, 4092- 4094. 